\title{
Improved real-time blood flow velocity quantification via application of the Karhunen-Loeve transform for increased signal-to-noise ratio
}

\author{
Samuel Ting ${ }^{*}$, Yu Ding, Orlando P Simonetti \\ From 2011 SCMR/Euro CMR Joint Scientific Sessions \\ Nice, France. 3-6 February 2011
}

\section{Objective}

Evaluate the application of temporal filtering via the Karhunen-Loeve Transform for increasing signal-tonoise ratio in real-time blood flow quantification.

\section{Background}

Real-time blood flow velocity quantification requires fast acquisition time and both high spatial and temporal resolution in order to capture clinically relevant features. Multi-coil parallel imaging techniques trade fast realtime cine acquisition with high temporal resolution for lower signal quality. Methods for increasing signal-tonoise ratio (SNR) will allow higher acceleration rates in parallel imaging, leading to faster acquisition times in

the context of exercise stress while maintaining signal quality.

Increased SNR via the Karhunen-Loeve Transform [1] (KLT) is achieved by decomposing a temporal cine sequence into a series of eigenmodes where the signal of interest is localized in a subset of eigenmodes and eliminating noise-only eigenmodes.

\section{Methods}

KLT was applied retrospectively to ten through-plane real-time velocity data sets of the aorta at rest acquired at $1.5 \mathrm{~T}$ (Avanto, Siemens, Malvern, PA). Optimal identification of noise-only eigenmodes was determined using the Marcenko-Pastur Law [2], and SNR gain was

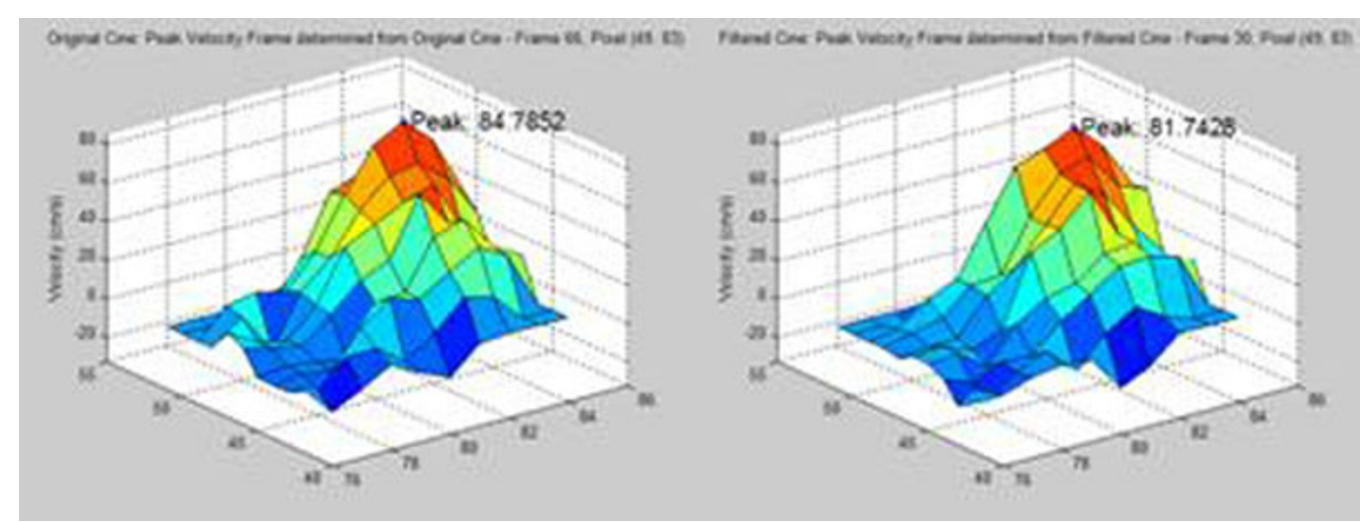

Figure 1 Velocity profiles showing peak velocity measurement for original real-time cine (left) and KLT filtered cine (right). 
calculated as the square root of the ratio of noise-only eigenmodes to total number of eigenmodes.

\section{Results}

Optimal selection of SNR gain via the Marcenko-Pastur Law results in SNR increase of $61.5 \pm 3.7 \%$ (mean \pm standard deviation) with no statistically significant difference in peak velocity measurement (Difference: $1.45 \pm 2.98 \%$, p-value: 0.2794). Figure 1 illustrates the minimal difference in peak velocity measurement due to KLT filtering.

\section{Conclusions}

Temporal filtering of real-time velocity images via KLT results in significant gains in SNR with minimal velocity profile smoothing and minimal effect on peak velocity measurement and may be useful in improved blood flow velocity quantification.

Published: 2 February 2011

\section{References}

1. Phys. Med. Biol 2009, 54:3909.

2. Mag. Res. Med. 2010, 63:782-789.

doi:10.1186/1532-429X-13-S1-P38

Cite this article as: Ting et al:: Improved real-time blood flow velocity quantification via application of the Karhunen-Loeve transform for increased signal-to-noise ratio. Journal of Cardiovascular Magnetic Resonance 2011 13(Suppl 1):P38.

Submit your next manuscript to BioMed Central and take full advantage of:

- Convenient online submission

- Thorough peer review

- No space constraints or color figure charges

- Immediate publication on acceptance

- Inclusion in PubMed, CAS, Scopus and Google Scholar

- Research which is freely available for redistribution

Submit your manuscript at www.biomedcentral.com/submit 